\title{
Expected professional and personal characteristics of clinical mentors: Differences between physiotherapy and social gerontology students
}

\author{
Bojana Filej ${ }^{1,2,3}$, Boštjan Žvanut ${ }^{4}$ Boris Miha Kaučič¹,2*
}

${ }^{1}$ Alma Mater Europaea - ECM, Maribor, Slovenia, ${ }^{2}$ College of Nursing in Celje, Slovenia, ${ }^{3}$ Faculty of Health Sciences, University of Novo Mesto, Slovenia, ${ }^{4}$ Faculty of Health Sciences, University of Primorska, Izola, Slovenia

\begin{abstract}
Background: Clinical mentors play a very important role in the development of knowledge and the acquisition of competencies of different health professionals. The success of the entire mentoring process also depends on the professional and personal characteristics of the clinical mentor. The purpose of the study was to identify which professional and personal characteristics of clinical mentors are relevant to physiotherapy (PHT) and social gerontology (SG) students.
\end{abstract}

Methods: The web survey was performed between January 20 and May 15, 2018, using the adapted version of nursing clinical teacher effectiveness inventory. The final sample consisted of 100 PHT and SG students from one of the Slovenian Universities.

Results: The competencies "explains clearly" $(p<0.001)$ and "takes responsibility of own actions" $(p=0.023)$ were statistically significantly more relevant to PHT students than to the SG students. The competencies "explains clearly" ( $p<0.001)$, "demonstrates clinical skill and judgment" $(p=0.033)$, "takes responsibility of own actions" ( $p=0.023)$, and "is self-critical" ( $p=0.023)$, were statistically significantly more relevant to PHT than to the SG students, while the statements "discusses current development in his/her field" ( $p=0.002)$, "communicates expectations of students" ( $p=0.029)$, "demonstrates empathy" ( $p=0.037)$, "demonstrates enthusiasm" ( $p=0.005)$, and "has a good sense of humor" $(p=0.005)$ were statistically significantly more relevant to SG students.

Conclusion: The contrast in responses reflects the differences in the nature of both professions: The predominantly instrumental nature of PHT and the predominantly expressive nature of SG

Key words: Clinical environment; mentor; student; physiotherapy; social gerontology

\footnotetext{
*Corresponding author: Boris Miha Kaučič, Alma Mater Europaea - ECM, Slovenska ulica 17, 2000 Maribor, and College of Nursing in Celje, Mariborska cesta 7, 3000 Celje.

E-mail: miha.kaucic@almamater.si
}

Submitted: 17 August 2018/Accepted: 20 November 2018

\section{INTRODUCTION}

Mentoring is an elusive term that has existed for years in many disciplines (1). The general purpose of mentoring is to offer support to the less experienced, young individual (2), to acquire the appropriate knowledge and competencies for the exercise of the profession, and to empower students for a 
professional, responsible and high-quality implementation of their profession (3).

There is no universal agreement on the definition of clinical practice mentoring, and therefore mentoring approaches vary considerably (4). In Slovenia, clinical training is also implemented in various ways, which depends on a number of factors, such as the number of employees in the educational institution, the requirements of teaching institutions, and the number of mentors in teaching institutions. The status of teaching institution is confirmed by the Ministry of Health. The possibilities of the implementation of clinical practice mentoring in the education process of health-care professionals are as follows: (a) A school mentor teaches skills by being present at the department for the duration of the clinical training, (b) the school mentor is present in the clinical environment every day, but only for a limited period of time, and (c) the school mentor is present only occasionally, for example, before the beginning and at the end of the clinical training and in case of potential problems. Clinical mentors are chosen by the institutions themselves on the basis of the formal requirements (the level of education and 3 years of work experience) as well as on the basis of informal requirements (personal characteristics and the ability to transfer knowledge). Clinical mentors should plan and organize the course of clinical student training (5).

Mentoring has been shown to help students overcome difficulties, discuss problems, and fulfill goals (6). To be effective in the implementation of mentoring, besides demonstrating professional competence, the mentor also has to exhibit certain personal attributes, which are very important in clinical practice (7). Mentors are not only instrumental in socializing students into professional behaviors and practice but can also significantly influence student careers and assist in their professional growth through advising and supporting their skills development and personal growth $(8,9)$. Different authors define the required mentors' competencies differently. Whittaker and Cartwright (10) summarized the following abilities of a successful mentor: Listen and hear what is said, question and challenge their own thinking and the thinking of other, summarize and reflect back, give and receive, constructive feedback, point out connections and contradictions, display empathy and understanding, encourage problem-solving and seek solutions, recognize and acknowledge emotions, trust others and be trusted by others, be open and honest with self and others, be a "tough" friend, give as well as receive unconditional time and space. Buchel and Edwards (7) have chosen 15 attributes of effective mentors, whereas Mogan and Knox (11) have collected 48 affirmations that describe characteristics of a clinical mentor, grouped into five categories: Teaching ability, nursing competence, evaluation, interpersonal relations, and personality. Haidar (12) states that a mentor should possess certain qualities, such as empathy, maturity, self-confidence, resourcefulness, and willingness to devote their time and energy to the student through several roles, such as a teacher, adviser, agent, role model, coach, and confidante.

The goal of our study was to identify: (i) What are the characteristics of a good mentor, and (ii) to identify the differences in the ideal image of a clinical mentor between the physiotherapy (PHT) (hereinafter PHT) and social gerontology (SG) (hereinafter SG) BSc students, who train for two entirely different professions, both of which, however, require developed interpersonal skills.

\section{METHODS}

A quantitative research approach was applied. A descriptive, causal non-experimental method was used.

\section{Instrument description}

The Nursing Clinical Teacher Effectiveness Inventory (NCTEI) (13) was used. The initial instrument was translated into Slovenian language through the following steps (14): (i) Forward translation by two experts, independently; (ii) back translation; (iii) comparison of the original and the translated version by another two experts; (iv) revision of the translated questionnaire; (v) test of the translated questionnaire for clarity by five Slovenian students; and finally (vi) by conducting a pilot study. To adapt the instruments to our population, the category "nursing competence" was paraphrased into "competences required in the field of expertise."

To identify mentors' characteristics (represented as NCTEI items), which are important to the target population, the respondents were invited to rank 
the items within each category. Hence, the items were not evaluated on a seven-point Likert scale, as was the case in the original instrument. The items required for the collection of the demographic data (e.g., study program, year of study, employment, years of work experience, and age) were included at the beginning of the questionnaire.

\section{Population sample}

The web-based questionnaire was distributed to 478 part-time PHT and SG (BSc) students of all study years at one of the Slovenian Universities. We received a response from 120 (25.3\%) PHT to 95 (19.8\%) SG students. The final sample consisted of 100 responses (response rate 20.9\%): 43 (43\%) responses from PHT and 57 (57\%) responses from SG students, because of the exclusion criteria (i) the response was interrupted; or, (ii) there was no response on two or more sections of the questionnaire. The sample details are presented in Table 1.

\section{Research procedures and data processing}

The web questionnaire was distributed to the participants by the Student Affairs Office through their emails. The responses were anonymous; all participants had the right to withdraw from the study before or during the questionnaire completion without any consequences. Participants were informed about all study details in the preface to the questionnaire. The data were collected between January 20 and May 15, 2018.

\section{Statistical analysis}

The data were analyzed with the programs IBM SPSS 21.0 and Microsoft Excel 2016. Univariate (calculation of average value, standard deviation, frequencies, and percent) and bivariate analysis (Mann-Whitney U-test) were applied. A significance level of $5 \%$ was used $(p=0.05)$.

\section{RESULTS}

Table 2 presents the average values $(\bar{x})$, standard deviations $(\sigma)$ and within category ranks (r) of PHT and SG students' responses along with the results of the Mann-Whitney U-test. In the continuation of the document, only the relevant results are presented.

In the category "teaching ability," the characteristic
TABLE 1. Sample details

\begin{tabular}{lcc}
\hline Variable & \multicolumn{2}{c}{ Study program ${ }^{*}$} \\
\cline { 2 - 3 } & PHT & SG \\
\hline Age (SD) & $25.5(6.8)$ & $26.1(8.8)$ \\
Sample size (\%) & $43(43)$ & $57(57)$ \\
Study year (\%) & & \\
Year 1 & $24(55.8)$ & $24(42.1)$ \\
Year 2 & $11(25.6)$ & $13(22.8)$ \\
Year 3 & $8(18.6)$ & $20(35.1)$ \\
Employed in (\%) & & \\
Hospital & $1(2.4)$ & $1(1.8)$ \\
Health center & $2(4.8)$ & $3(5.3)$ \\
Social welfare institution & $2(4.8)$ & $5(8.8)$ \\
Private clinic & $1(2.4)$ & $2(3.5)$ \\
Unemployed & $26(61.9)$ & $31(54.4)$ \\
Other & $10(23.8)$ & $15(26.3)$ \\
No response & $1(2.3)$ & 0 \\
Years of work experience (\%) & & \\
No response & $15(34.9)$ & $16(28.1)$ \\
$<6$ & $16(37.2)$ & $27(47.4)$ \\
6-10 & $4(9.3 \%)$ & $1(1.8)$ \\
11-15 & $5(11.6)$ & $5(8.8)$ \\
16-20 & 0 & $2(3.5)$ \\
$21-25$ & $3(7.0)$ & $5(8.8)$ \\
$>25$ & 0 & $1(1.8)$ \\
\hline
\end{tabular}

*PHT: Physiotherapy, SG: Social gerontology, SD: Standard deviation

"explains clearly" was selected as the most important characteristic of a clinical mentor by both PHT and SG students. Furthermore, a statistically significant difference between the responses of PHT and SG students was identified for this characteristic $(p<0.001)$, the average rank value is lower for PHT $(\bar{x}=2.7 ; \sigma=3.0)$ than for SG students $(\bar{x}=5.0$; $\sigma=3.6$ ). On the other hand, both groups selected "quickly grasps what students are asking or telling" as a less important characteristic in the aforementioned category. The difference between the highest and the lowest average values in the category "teaching ability" is 7.9 for the PHT and 4.5 for SG students (Table 3), which indicates that PHT students gave more consistent responses regarding the items in this category than SG students.

In other categories, substantial differences were identified in the ranking of the relevance of mentor's characteristics between PHT and SG students. 
TABLE 2. Descriptive statistics, within category ranks (r) of PHT and SG students' responses with the results of the Mann-Whitney U-test

\begin{tabular}{|c|c|c|c|c|c|c|c|}
\hline \multirow[t]{3}{*}{ Category/Statement } & \multicolumn{6}{|c|}{ Study program } & \multirow{3}{*}{$\begin{array}{c}\text { MW test } \\
P\end{array}$} \\
\hline & \multicolumn{3}{|c|}{ PHT } & \multicolumn{3}{|c|}{ SG } & \\
\hline & $\bar{x}$ & $\sigma$ & $r$ & $\bar{x}$ & $\sigma$ & $\mathrm{r}$ & \\
\hline \multicolumn{8}{|l|}{ Teaching ability } \\
\hline Explains clearly & 2.7 & 3.0 & 1 & 5.0 & 3.6 & 1 & $<0.001$ \\
\hline Emphasizes what is important & 4.8 & 3.0 & 2 & 6.1 & 4.0 & 4 & 0.174 \\
\hline Encourages students to gain knowledge and skills & 7.1 & 3.3 & 6 & 6.0 & 4.1 & 3 & 0.123 \\
\hline Remains accessible to students when they need them & 5.6 & 3.2 & 3 & 5.3 & 3.8 & 2 & 0.470 \\
\hline Guides students' development of clinical skills & 6.2 & 3.6 & 5 & 6.5 & 3.5 & 5 & 0.670 \\
\hline Ensures additional improvement in knowledge and skills & 9.9 & 3.6 & 12 & 8.9 & 3.5 & 10 & 0.122 \\
\hline Offers special help when difficulties arise & 5.6 & 2.9 & 4 & 6.7 & 3.7 & 6 & 0.181 \\
\hline Is well prepared for teaching & 7.2 & 3.5 & 7 & 7.5 & 3.9 & 7 & 0.588 \\
\hline Enjoys teaching & 8.7 & 4.2 & 10 & 8.2 & 4.5 & 9 & 0.549 \\
\hline Encourages active participation in discussion & 8.7 & 3.4 & 9 & 9.1 & 3.5 & 12 & 0.531 \\
\hline Quickly grasps what students are asking or telling & 10.6 & 3.0 & 14 & 9.5 & 3.4 & 14 & 0.128 \\
\hline Answers carefully and precisely questions raised by students & 10.3 & 3.2 & 13 & 9.1 & 3.7 & 13 & 0.070 \\
\hline Helps students organize their thoughts about patient problems & 9.3 & 3.7 & 11 & 9.0 & 3.8 & 11 & 0.644 \\
\hline Promotes student independence & 8.3 & 3.5 & 8 & 8.2 & 3.9 & 8 & 0.872 \\
\hline \multicolumn{8}{|l|}{ Competencies required in the field of expertise } \\
\hline Demonstrates clinical skill and judgment & 3.0 & 2.4 & 1 & 4.0 & 2.5 & 2 & 0.033 \\
\hline Demonstrates communication skills & 4.9 & 2.3 & 6 & 4.2 & 2.2 & 3 & 0.152 \\
\hline Reveals broad reading in his/her area of interest & 4.7 & 2.4 & 5 & 4.3 & 2.4 & 4 & 0.348 \\
\hline Discusses current development in his/her field & 7.0 & 2.1 & 9 & 5.9 & 2.0 & 8 & 0.002 \\
\hline Directs students to useful literature & 6.1 & 2.3 & 7 & 5.6 & 2.5 & 6 & 0.312 \\
\hline Demonstrates a breadth of knowledge & 3.7 & 2.1 & 2 & 4.0 & 2.7 & 1 & 0.977 \\
\hline Recognizes own limitations & 6.3 & 1.9 & 8 & 6.3 & 2.2 & 9 & 0.896 \\
\hline Takes responsibility of own actions & 4.5 & 2.2 & 3 & 5.6 & 2.5 & 7 & 0.023 \\
\hline Is a good role model & 4.7 & 2.9 & 4 & 5.1 & 3.0 & 5 & 0.460 \\
\hline \multicolumn{8}{|l|}{ Evaluation } \\
\hline Makes specific suggestions for improvement & 4.2 & 2.2 & 2 & 4.2 & 2.1 & 1 & 0.942 \\
\hline Provides frequent feedback on students' performance & 4.7 & 2.2 & 6 & 4.8 & 2.4 & 8 & 0.731 \\
\hline Identifies students' strengths and limitations objectively & 4.3 & 2.0 & 3 & 4.7 & 2.0 & 7 & 0.272 \\
\hline Observes students' performance frequently & 5.0 & 2.2 & 7 & 4.6 & 2.0 & 5 & 0.343 \\
\hline Communicates expectations of students & 5.4 & 2.3 & 8 & 4.3 & 2.4 & 3 & 0.029 \\
\hline $\begin{array}{l}\text { Gives students positive reinforcement for good contributions, observations, } \\
\text { or performance }\end{array}$ & 4.3 & 2.4 & 4 & 4.3 & 2.2 & 2 & 0.942 \\
\hline Corrects students' mistakes without belittling them & 3.7 & 2.2 & 1 & 4.4 & 2.2 & 4 & 0.108 \\
\hline Does not criticize students in front of others & 4.5 & 2.5 & 5 & 4.7 & 2.9 & 6 & 0.670 \\
\hline \multicolumn{8}{|l|}{ Interpersonal Relations } \\
\hline Provides support and encouragement to students & 2.9 & 1.6 & 1 & 3.4 & 1.6 & 3 & 0.073 \\
\hline Is approachable & 3.5 & 1.6 & 4 & 3.4 & 1.9 & 4 & 0.827 \\
\hline Encourages a climate of mutual respect & 3.3 & 1.6 & 3 & 3.3 & 1.7 & 2 & 0.943 \\
\hline Listens attentively & 3.9 & 1.6 & 5 & 4.0 & 1.3 & 6 & 0.857 \\
\hline Shows a personal interest in students & 2.9 & 1.5 & 2 & 3.0 & 1.8 & 1 & 0.874 \\
\hline
\end{tabular}


TABLE 2. (Continued)

\begin{tabular}{|c|c|c|c|c|c|c|c|}
\hline \multirow[t]{3}{*}{ Category/Statement } & \multicolumn{6}{|c|}{ Study program } & \multirow{3}{*}{$\begin{array}{c}\text { MW test } \\
P\end{array}$} \\
\hline & \multicolumn{3}{|c|}{ PHT } & \multicolumn{3}{|c|}{ SG } & \\
\hline & $\bar{x}$ & $\sigma$ & $r$ & $\bar{x}$ & $\sigma$ & $r$ & \\
\hline Demonstrates empathy & 4.5 & 1.8 & 6 & 3.8 & 1.8 & 5 & 0.037 \\
\hline \multicolumn{8}{|l|}{ Personality } \\
\hline Demonstrates enthusiasm & 5.4 & 2.1 & 7 & 4.2 & 2.1 & 2 & 0.005 \\
\hline Is a dynamic and energetic person & 3.8 & 2.1 & 2 & 4.6 & 2.1 & 5 & 0.051 \\
\hline Self-confidence & 4.6 & 2.3 & 5 & 4.2 & 2.1 & 3 & 0.382 \\
\hline Is self-critical & 4.4 & 2.0 & 4 & 5.4 & 2.3 & 8 & 0.023 \\
\hline Is open-minded and non-judgmental & 2.7 & 1.9 & 1 & 3.4 & 2.2 & 1 & 0.111 \\
\hline Has a good sense of humor & 6.3 & 1.9 & 8 & 5.1 & 2.2 & 7 & 0.005 \\
\hline Appears organized & 4.0 & 2.0 & 3 & 4.3 & 2.5 & 4 & 0.612 \\
\hline
\end{tabular}

PHT: Physiotherapy, SG: Social gerontology, MW: Mann-Whitney U-test, r: rank within a category, $\sigma:$ Standard deviation

TABLE 3. Differences between the highest and lowest average values within each category

\begin{tabular}{lcc}
\hline Category & \multicolumn{2}{c}{ Study program } \\
\cline { 2 - 3 } & PHT & SG \\
\hline Teaching ability & 7.9 & 4.5 \\
Competences in the field of expertise & 4.0 & 2.3 \\
Evaluation & 1.7 & 0.6 \\
Interpersonal relations & 1.6 & 1.0 \\
Personality & 3.6 & 2.0 \\
\hline
\end{tabular}

PHT: Physiotherapy, SG: Social gerontology

The only exception is the characteristic "is openminded and non-judgmental" (category "personality"), which was evaluated as the most important characteristic by both groups. Another interesting result is the bigger difference between the highest and lowest average for PHT students than for SG students, which is present in all categories (Table 3). This indicates more consistent responses of PHT students, compared with SG students. Furthermore, the difference between the highest and lowest average is substantially higher in the category "teaching ability" than in the other categories.

Statistically significant differences between both groups were identified for three out of nine characteristics in the category "competences required in the field of expertise," namely for the item "demonstrates clinical skill and judgment” ( $p=0.033)$, which is according to the results more important to PHT ( $\bar{x}=3.0, \sigma=2.4)$ than to SG students $(\bar{x}=4.0, \sigma=2.5)$; the item "discusses current development in his/her field" ( $p=0.002)$, which is more important to SG $(\bar{x}=5.9, \sigma=2.0)$ than to PHT students $(\bar{x}=7.0, \sigma=2.1)$; and also for the item "takes responsibility of own actions" ( $p=0.023)$, which is also more important to PHT $(\bar{x}=4.5, \sigma=2.2)$ than to SG students $(\bar{x}=5.6, \sigma=2.5)$.

In the category "evaluation," the item "communicates expectations of students" resulted as significantly $(p=0.029)$ more important to SG $(\bar{x}=4.3$, $\sigma=2.4)$ than to PHT students $(\bar{x}=5.4, \sigma=2.3)$. The item "demonstrates empathy" in the category "interpersonal relations," resulted as significantly ( $p=0.037)$ more important to SG $(=3.8, \sigma=1.8)$ than to PHT students $(\bar{x}=4.5, \sigma=1.8)$. In the category "interpersonal relationship," no significant differences in responses between the groups were identified. However, in the category "personality" three competences out of eight resulted as significantly different between PHT and SG students, namely: "Demonstrates enthusiasm" ( $p=0.005)$, "is self-critical" ( $p=0.023)$, and "has a good sense of humor" ( $p=0.005)$. The mentor's competences "demonstrates enthusiasm" and "has a good sense of humor" are more important to SG than to PHT students; on the other hand, the competence "is self-critical" is more important to PHT than to SG students (Table 2).

\section{DISCUSSION}

Our results indicate substantial differences in the desired characteristics of a clinical practice mentor between PHT and SG students (Table 2). According to PHT students, the most important characteristics 
of a good mentor are that he or she clearly explains and demonstrates interventions, demonstrates clinical skills, corrects students' mistakes without belittling them, gives students positive reinforcement and support, and is open-minded and non-judgmental. On the other hand, the SG students consider as the most important the following characteristics of the mentor: Explains carefully and understandably, reveals broad reading in his or her area of interest, offers suggestions for improvement, shows personal interest in students, and that he or she is open-minded and non-judgmental.

In Slovenia, PHT study program has been implemented since 1950. Its primary purpose is to train students for the development and the restoration of mobility and functional ability of people and the maintenance of functional ability of healthy people of all ages (15). On the other hand, the SG program is still a new study program in Slovenia. SG is a multidisciplinary field with an emphasis on the responsibility of the social gerontologists to deal with the integration of the elderly in the society, helping the elderly to adapt to the environment and vice versa (16).

Buchel and Edwards (7) have conducted a survey in which they wanted to identify the three most important and three least important characteristics of an effective clinical mentor. They collected 15 characteristics, which they defined for the simplified understanding of the respondents. In the final sample, 179 mentors and 117 lecturers were involved in the study, who ranked the following three characteristics of a mentor as the most important: Clinical competency, non-judgmental, role model, and the following three characteristics as the least important: Scholarly activity, organization skills, and well prepared. Mentors have ranked enthusiasm among the most important characteristic in the aforementioned study. Our results, performed on students, are consistent with the aforementioned study. Furthermore, PHT students ranked the characteristics "demonstrates clinical skills and judgment" and "demonstrates a breadth of knowledge" as the two most important characteristics for both groups of students in the category "competencies required in the field of expertise" (Table 2). Furthermore, the characteristic "is open-minded and non-judgmental" was ranked as the most important characteristic in the category "personality" by both groups.

Interestingly, in both PHT and SG groups, the characteristic "is a good role model" was not ranked as the most important in the category "competencies required in the field of expertise". In fact, PHT students ranked it as the fourth and SG students as the fifth most important mentor's competence in this category. These results are in contrast with findings of Finnerty and Collington (17), who emphasized the importance of role modeling by the mentor as vital for the students. However, their results were based on the analysis of audio-diaries, which were completed by midwifery students over 10 days in clinical practice and were transcribed using discourse analysis. Furthermore, the characteristic "demonstrates enthusiasm" in the category "personality" is significantly (Table $2, p<0.005$ ) less important for the PHT (ranked $7^{\text {th }}$ ) than for the SG students (ranked $2^{\text {nd }}$ ). Furthermore, Buchel and Edwards (7) state in their research that those educators who demonstrate enthusiasm for their educational duties and responsibilities are ranked as the best ones. Why is enthusiasm more important to the students of SG than to the students of FTH would still have to be established, maybe because SG is a new profession and therefore all of the professionals in the education process feel obliged to promote it to make it recognizable. The characteristics "is well prepared for teaching" and "appears organized" in the category "personality" are ranked as the characteristics of medium relevance.

Elcigil and Sari (18) have studied the characteristics of effective clinical mentors. In the qualitative study, 24 nursing last-year BSc students highlighted 20 characteristics of mentors. These were grouped into five categories according to Gignac-Caille and Oermann (19). They are observing that clinical mentors should have good communication skills and should not have a critical or offensive attitude and should defend students more often if the necessity arises. However, our study indicates completely different results, as SG students ranked the characteristic "demonstrates communication skills" as the third most important, and PHT students as the sixth most important in the category "competencies required in the field of expertise." The difference in the importance, contributed to communication skills, might stem from the basic mission of both professions. 
The profession of SG requires wider communication skills, not only with the elderly but also with the wider local community, while communication skills in performing the PHT profession are usually limited to the communication with the patients and the colleagues in their team. In our study, however, there emerged one unexpected result. Attentive listening, which is an important communication skill, was ranked as the least important by both groups of students. Such an assessment by the students is unexpected, as Allison-Jones and Hirt (20) indicate that communication between the tutor and the students is an important part of the education process and that, according to Elcigil and Sari (18) a good conversation between the student and the mentor is the basis for the establishment of mutual trust, good communication, respect, and empathy. Furthermore, Jahan et al. (21) believe that better educators are those who have effective and good communication skills. Finnerty and Collington (17) in their survey emphasize the importance of attentive listening and non-verbal communication of the mentor. Jokelainen et al. (4) have through a review of scientific articles established (1986-2006), that communication skills in interaction with patients included also teaching and advising on how to use different methods in real care situations and also guiding students in meeting patients, communicating, and cooperating with them.

According to our results, open-mindedness and non-judgmental attitude of a clinical mentor is very important to both PHT and SG students. Furthermore, the characteristic "corrects students' mistakes without belittling them" in the category "evaluation" also resulted as important, especially to PHT students. Feedback is an essential part of mentoring. This involves discussing what has gone right, starting with students' opinions of their own strengths followed by mentors' views, and the discussion of the required improvements starting again with the students' opinions followed by those of the mentors' (12). Lorber and Donik (22) have interviewed nurses clinical mentors, who evaluated 22 personal features and then ranked the 10 most important ones. The characteristics that every clinical mentor should possess are the following: Professionalism, the appropriate level of education, honesty, good communication skills, responsibility, reliability, activity at work, collegiality, creativity, and determination. The results of our study show that both groups of students appreciate the mentor's expert knowledge (Table 2: Characteristic "demonstrates a breadth of knowledge," by the PHTs ranked as the $2^{\text {nd }}$; and by the SGs ranked as the $1^{\text {st }}$ in the category "competence in the area of expertise"). PHT students also emphasized the importance of mentor's responsibility, as the characteristic "takes responsibility for their own actions" was ranked as the third in the aforementioned category.

Harrington (23) states five most important features of a mentor: Being an authority in the field, an educator, a counselor, a sponsor, and having a personal commitment. These characteristics were chosen by 565 nurses with $0-15$ year experience in mentorship. This is in contrast with the results of our study, as the characteristics "is well prepared for teaching" and "enjoys teaching" (Table 2, category "teaching ability") were ranked between the $7^{\text {th }}$ and $10^{\text {th }}$ place, i.e. as non-relevant by both groups of students. This is also in contrast to Beitz and Wieland (24), who emphasizes that the ability to teach is one of the most important features of a mentor.

Williams and Grant (25) state the following characteristics of a mentor: Empathy, active listening skills, open questioning, honesty, and being non-judgmental. The empathy of a clinical mentor is not considered to be an important characteristic of the PHT and SG students.

Jahan et al. (21) have conducted research among 119 students and 89 lecturers, to establish the characteristics of an efficient mentor. The characteristics had to be ranked from 1 (most important) to 13 (least important). They found out that the most important characteristic is the interest in teaching, followed by knowledge, clinical competence, and that the mentor is non-judgmental and possesses good communication skills. Furthermore, Buchel and Edwards (7) agree that clinical competence is among the most important characteristics of an effective clinical teacher and that better educators are those who demonstrate enthusiasm for their educational responsibilities.

Furthermore, Mogan and Knox (11) have studied the differences in the students' and lecturers' responses to ten characteristics of good and bad 
clinical mentors. The assessments of the characteristics of a good clinical mentor do not differ significantly between both groups. Students stated as the most important the following characteristics: Is a good role model, enjoys nursing, demonstrates clinical skills and judgment, enjoys teaching, is well prepared for teaching, takes responsibility for own actions, is approachable, and is self-confident. The aforementioned characteristics were selected also by the group of teachers, however, in a slightly different order.

\section{CONCLUSION}

The first limitation of our study is predominantly in the different definitions of clinical mentor competencies. In fact, in some definitions also personal characteristics of clinical mentors are included in the competencies of a clinical mentor, whereas other definitions focus strictly on the professional competencies for the implementation of mentorship. The second limitation is in the low number of respondents in our study; therefore, the generalization of the results should be made with much consideration. From the desired characteristics of a clinical mentor, as defined by the PHT and SG students, it can be observed that the comparison of the stated characteristics between the two groups of students is difficult, as they are in the process of education for two very different professions.

The central subjects in the education and training process are the students; therefore, all of our endeavors should be focused on forming professionally qualified, responsible, and mature healthcare professionals with a rounded personality. Being a clinical mentor is a demanding role, involving a number of tasks and challenges, which can in many cases prove as decisive in the matter whether a young person will grow to love the profession he has been training for, or end up turning away from it in disappointment.

\section{REFERENCES}

1. Ehrich $L$, Tennent $L$, Hansford B. A review of mentoring in education: Some lessons for nursing. Contemp Nurse 2002;12(3):253-64.

https://doi.org/10.5172/conu.12.3.253.

2. Grossman SC. Mentoring in Nursing. A Dynamic and Collaborative Process. New York: Springer Publishing Company; 2007.
3. Bradbury-Jones C, Sambrook S, Irvine F. The meaning of empowerment for nursing students: A critical incident study. J Adv Nurs 2007;59(4):342-51.

https://doi.org/10.1111/j.1365-2648.2007.04331.x;

https://doi.org/10.1111/j.1365-2648.2007.04300.x.

4. Jokelainen M, Turunen H, Tossavainen K, Jamookeeah D, Coco K. A systematic review of mentoring nursing students in clinical placements. J Clin Nurs 2011;20(19-20):2854-67.

https://doi.org/10.1111/j.1365-2702.2010.03571.x.

5. Meden E, Kvas A, Hoyer S. A descriptive research on opinions of nursing students and clinical mentors on assessment of clinical practice. Obzor Zdrav Neg 2017;51(4):320-7.

https://doi.org/10.14528/snr.2017.51.4.157.

6. Macafee DA. Is there a role for mentoring in surgical specialty training? Med Teach 2008;30(2):e55-9.

https://doi.org/10.1080/01421590701798711.

7. Buchel TL, Edwards FD. Characteristics of effective clinical teachers. Fam Med 2005;37(1):30-5.

8. Al-Hamdan Z, Fowler J, Bawadi H, Morrie P, Summers L, Dowsett D. Student nurses' perceptions of a good mentor: A questionnaire survey of student nurses in the UK, USA and Jordan. Int J Humanit Soc Sci 2014;4(3):248-56

9. Edgecombe K, Jennings M, Bowden M. International nursing students and what impacts their clinical learning: Literature review. Nurse Educ Today 2013;33(2):138-42.

https://doi.org/10.1016/j.nedt.2012.07.015.

10. Whittaker M, Cartwright A. The Mentoring Manual. Aldershot, Hampshire: Brookfield, VT: Gower; 2000.

11. Mogan J, Knox JE. Characteristics of 'best' and 'worst' clinical teachers as perceived by university nursing faculty and students. J Adv Nurs 1987;12:331-7.

https://doi.org/10.1111/j.1365-2648.1987.tb01339.x.

12. Haidar E. Coaching and mentoring nursing students. Nurs Manag (Harrow) 2007;14(8):32-5.

https://doi.org/10.7748/nm2007.12.14.8.32.c8241.

13. Knox JE, Mogan J. Important clinical teacher behaviours as perceived by university nursing faculty, students and graduates. J Adv Nurs 1985; 10:25-30

https://doi.org/10.1111/j.1365-2648.1985.tb00488.x.

14. Råholm MB, Thorkildsen $K$, Löfmark $A$. Translation of the nursing clinical facilitators questionnaire (NCFQ) to Norwegian language. Nurse Educ Pract 2010;10(4):196-200.

https://doi.org/10.1016/j.nepr.2009.08.005

15. Presentation of Study Programme Physiotherapy 2014 University of Ljubljana: Faculty of Health Sciences. Available from: http://www.2.zf.uni-lj. si/si/1stopnja-2-2-1/fizioterapija-2-2-1-3/predstavitev-studijskega-programa-2-2-1-3-1. [Last cited on 2018 Nov 15].

16. Ranking of the Most Employable Vocations, n.d 2015. Available from: http://www.studij.si/novice/54/Lestvica-najbolj-zaposljivih-poklicev.html. [Last cited on 2018 Nov 15].

17. Finnerty G, Collington V. Practical coaching by mentors: Student midwives' perceptions. Nurse Educ Pract 2013;13(6):573-7. https://doi.org/10.1016/j.nepr.2012.09.016.

18. Elcigil A, Sari HY. Students' opinions about and expectations of effective nursing clinical mentors. J Nurs Educ 2008;47(3):118-23.

https://doi.org/10.3928/01484834-20080301-07.

19. Gignac-Caille AM, Oermann MH. Student and faculty perceptions of effective clinical instructors in ADN programs. J Nurs Educ 2001;40(8):347-53. 
20. Allison-Jones LL, Hirt JB. Comparing the teaching effectiveness of part-time and full-time clinical nurse faculty. Nurs Educ Perspect 2004;25(5):238-43.

21. Jahan F, Sadaf S, Kalia S, Khan A, Hamza HB. Attributes of an effective clinical teacher: A survey on students' and teachers' perceptions. J Coll Physicians Surg Pak 2008;18(6):357-61.

22. Lorber M, Donik B. Factors of Mentorship Process in Education of Nursing Care. Paper Presented at: Management, Izobraževanje in Turizem: Kreativno v Spremembe. Portorož: Univerza na Primorskem, Turistica in Fakulteta za Management; 2009. p. 1716-23.

23. Harrington S. Mentoring new nurse practitioners to accelerate their development as primary care providers: A literature review. J Am Acad Nurse Pract 2011;23(4):168-74.

https://doi.org/10.1111/j.1745-7599.2011.00601.x.

24. Beitz JM, Wieland D. Analyzing the teaching effectiveness of clinical nursing faculty of full-and part-time generic BSN, LPN-BSN, and RN-BSN nursing students. J Prof Nurs 2005;21(1):32-45. https://doi.org/10.1016/j.profnurs.2004.11.003.

25. Williams ZM, Grant A. Be a good mentor. Educ Prim Care 2012;23:56-8. https://doi.org/10.1080/14739879.2012.11494070. 